\title{
INTERAKSI SOSIAL ONLINE DAN KECEMASAN SOSIAL SEBAGAI PREDIKTOR KECANDUAN INTERNET PADA REMAJA
}

\author{
Putra Hidayat \\ Mahasiswa Pascasarjana Universitas Negeri Yogyakarta \\ Jl. Colombo Yogyakarta No.1, Karang Malang, Caturtunggal, \\ Kec. Depok, Kabupaten Sleman, Daerah Istimewa Yogyakarta \\ Surel : putraaa.hidayat@gmail.com
}

\begin{abstract}
This study aims to examine the effect of online social interaction and social anxiety on internet addiction in adolescents. Employing an ex-post facto design, this research was conducted in the regency of Purbalingga involving 366 teenagers as sample which was determined using a multistage random sampling techniques. Data were collected through questionnaires consisting of internet addiction questionnaires, online social interaction questionnaires, and social anxiety questionnaires. These instruments were validation through content validity and reliability based on Cronbach's Alpha coefficient. The data where then analysed by means of a multiple regression analysis. The results showed that there was a significant effect of online social interaction and social anxiety on internet addiction in adolescents $(p=0,000)$. Therefore, it can be concluded that there is a effect between online social interaction and social anxiety towards the adolescents internet addiction. Online social interaction and social anxiety can be strong predictors of internet addiction among adolescents.
\end{abstract}

Keywords: adolescents, internet addictions, interaction social online, social anxiety.

\begin{abstract}
Abstrak : Penelitian ini bertujuan untuk menguji pengaruh interaksi sosial online dan kecemasan sosial secara bersama-sama terhadap kecanduan internet pada remaja. Jenis penelitian ini adalah ex-post facto. Penelitian ini dilakukan di Kabupaten Purbalingga. Sampel yang digunakan sebanyak 366 orang remaja. Teknik pengumpulan sampel penelitian menggunakan teknik multistage random sampling, sedangkan untuk teknik pengumpulan data menggunakan angket. Angket penelitian ini terdiri dari angket kecanduan internet, angket interaksi sosial online, dan angket kecemasan sosial. Teknik validasi instrumen menggunakan validasi isi dan reliabilitas berdasarkan koefisien Alpha Cronbach. Teknik analisis data menggunakan analisis regresi berganda. Hasil penelitian menunjukkan bahwa terdapat pengaruh yang signifikan antara interaksi sosial online dan kecemasan sosial secara bersama-sama terhadap kecanduan internet pada remaja $(\mathrm{p}=0,000)$. Oleh karena itu, dapat disimpulkan bahwa ada pengaruh antara interaksi sosial online dan kecemasan sosial terhadap kecanduan internet pada remaja. Interaksi sosial online dan kecemasan sosial dapat menjadi prediktor yang cukup kuat terhadap kecanduan internet pada remaja.
\end{abstract}

Kata kunci: kecanduan internet, interkasi sosial online, kecemasan sosial, remaja

\section{PENDAHULUAN}

Internet sudah menjadi teknologi yang

internet untuk memenuhi berbagai kebutuhan digunakan banyak orang dan merupakan mereka seperti belajar, hiburan, bersosialisasi, salah satu yang paling berpengaruh di abad dan berbelanja (Lee dan $\mathrm{Wu}, 2013$; Wu dan 21. Orang-orang kini bergantung pada Peng, 2017). Kebutuhan internet tidak 
terbatas usia, dari anak-anak sampai orang tua membutuhkan internet, dan remaja merupakan kelompok usia yang paling banyak membutuhkan internet (Norris, 2007). Tanpa adanya internet, remaja akan merasa tertinggal dari berbagai informasi terbaru (Crutzen Nooijer, Brouwer, Oenema, Brug, dan de Vries, 2011).

Penggunaan internet dengan waktu penggunaan yang tidak terkendali dapat menjadikan orang-orang berisiko mengalami kecanduan internet. Hal ini terjadi karena pengguna lebih banyak menggunakan internet untuk game online dan interaksi sosial online (Lee, Ko, dan Chou, 2015). Peningkatan penggunaan internet juga disebabkan karena kemudahannya. Salah satu kemudahan internet yaitu bisa diakses dengan smartphone, hal ini yang menjadikan remaja berpotensi mengalami kecanduan internet (Kuss, Rooij, Shorter, Griffiths, dan Mheen, 2013).

Data survei APJII (2019) menunjukkan bahwa kelompok usia 10 sampai dengan umur 14 tahun mengalami peningkatan penggunakan internet sebesar $66,52 \%$. Pada usia 15 sampai dengan umur 19 tahun, terjadi peningkatan sebesar 91\%. Pada usia 20 sampai dengan umur 24 tahun, terjadi peningkatan sebesar 88,5\%. Pada usia 25 sampai 54 tahun, terjadi peningkatan sebesar $82,7 \%$ dan pada usia diatas 54 tahun, terjadi peningkatan sebesar 47,6\%. Hasil ini menunjukkan bahwa remaja mengalami peningkatan penggunaan internet tertinggi dan menunjukkan bahwa sebagian besar remaja telah menjadi pengguna internet.

Remaja membutuhkan internet untuk memperbarui informasi, menyelesaikan tugas, mengisi waktu luang, sosialisasi, pendidikan, dan hiburan (APJII, 2017; Kepala Pusat Informasi dan Humas Kementrian Kominfo, 2014). Kebutuhan remaja pada internet yang tinggi memunculkan permasalahan psikologis dan permasalahan perilaku berupa kecanduan internet (Lee, Ko, dan Chou, 2015).

Kecanduan internet merupakan gejala gangguan mental dan gangguan perilaku yang terjadi karena penggunaan internet yang terus-menerus (Shaw dan Black, 2008). Beberapa ciri-ciri kecanduan internet terlihat dari kepribadian tertentu seperti pengendalian diri, impulsif, dan lima besar kepribadian yaitu keterbukaan, extraversion, conscientiousness, agreeableness, neuroticism (Musetti et al., 2016; Zhou, Li, Li, Wang, dan Zhao, 2017).

Orang yang mengalami kecanduan internet akan mengalami berbagai permasalahan. Kecanduan internet juga akan memengaruhi kondisi fisik, emosional, dampak negatif pada hubungan personal, dan perkembangan sosial (Nakaya, 2015:9). Selain itu kecanduan internet juga dapat berakibat pada kematian akibat serangan 
jantung, yang disebabkan oleh gangguan fisik seperti insomnia, dan kurang olahraga.

Menurut Jiang (2014), tingkat durasi waktu terhubung internet (internet connectedness) yang tinggi cenderung menunjukkan gejala kecanduan internet. Young (1998) membedakan pengguna internet menjadi dua yaitu pengguna internet secara normal (non dependent) yang mengakases internet empat sampai lima jam per minggu, dan kategori pengguna internet adiktif (dependent) yang mengakses internet sebanyak 20 sampai 80 jam per minggu.

Salah satu penyebab seseorang mengalami kecanduan internet adalah interaksi sosial online (Perdew, 2014). Interaksi sosial online menurut Horrigan (2005) yaitu suatu hubungan antara individu yang bertemu dalam masyarakat online untuk menghabiskan waktu dengan orang lain, berteman dengan orang baru, mengembangkan hubungan dan saling bertukar hubungan emosional. Penelitian Lee dan Cheung, (2014) menunjukkan bahwa dari 212 pengguna facebook yang secara sukarela berpartisipasi antara umur 16 sampai dengan 25 tahun mengalami kecanduan internet karena lebih menyukai menggunakan interaksi sosial online daripada interaksi sosial.

Permasalahan yang muncul pada remaja yang menggunakan interaksi sosial online yaitu akan menjadikan remaja melakukan perilaku anonim di internet dengan mengatakan suatu kebohongan atau melakukan hal-hal di internet yang tidak mereka lakukan pada kegiatan offline. Selain itu remaja akan kehilangan waktu tidur mereka karena online berlebihan, lupa makan, dan olah raga.

Peningkatan penggunaan interaksi sosial online akan berakibat seseorang mengalami kecanduan internet. Remaja yang melakukan interaksi sosial online dengan orientasi untuk memiliki lebih banyak teman online dapat mengalami kecanduan internet (Smahel Brown, dan Blinka, 2012).

Penyebab lain dari kecanduan internet adalah kecemasan sosial (Martin 2008: 5253). Lanjut dikatakan bahwa kecemasan sosial adalah perasaan takut dan cemas yang berlebihan akan situasi sosial tertentu. Penelitian Ko, Liu, Wang, Chen, Yen, dan Yen, (2014) menunjukkan bahwa dari 2353 ada 1382 remaja kecanduan internet karena mereka mengalami kecemasan sosial. Tingginya pengaruh kecemasan sosial pada remaja di kedua penelitian tersebut berakibat pada prestasi akademik dan motivasi untuk belajar yang menurun.

Pada penelitian yang dilakukan oleh Young (1998) menemukan bahwa 34\% dari mereka yang kecanduan internet memiliki riwayat gangguan kecemasan. Hal itu menjadi teori awal yang menunjukkan penyebab keterkaitan remaja pada internet 
karena menariknya internet sebagai media yang dapat diterima secara sosial untuk digunakan sebagai sarana melepaskan diri dari kecemasan sosial (Martin dan Schumacher, 2003).

$$
\text { Penelitian Merikangas }
$$
menunjukkan bahwa remaja dengan usia 13 sampai dengan umur 18 tahun memiliki kecemasan sosial sebanyak 5,5\%, dan ada $1,3 \%$ diantaranya mengalami kecemasan sosial tinggi. Data lainnya menunjukkan bahwa terdapat $3,9 \%$ remaja umur $13-14$ tahun, mengalami kecemasan sosial, di luar itu ada 6,1\% remaja berumur 15 sampai dengan umur 16 tahun, dan 6,9\% remaja dengan usia 17 sampai dengan umur 18 tahun yang juga mengalami kecemasan sosial. Berdasarkan data tersebut menunjukkan kecemasan sosial puncaknya pada masa remaja.

Kecemasan sosial memengaruhi kemampuan individu untuk dapat bersosialisasi secara efektif dan menyesuaikan diri dengan lingkungan yang baru. Penelitian menunjukkan bahwa orangorang yang mengalami situasi kecemasan sosial akan membangkitkan rasa takut dan reaksi yang lebih parah dan biasanya didiagnosis pada usia remaja serta lebih signifikan terkena dampak sepanjang umur mereka (Fonseca, 2015: 7).

Seseorang yang sedang mengalami kecemasan sosial akan mengatasi kecemasan sosial yang dimilikinya dengan melarikan diri dari dunia nyata ke dunia maya, akibatnya ketika harus berinteraksi dengan orang lain di dunia nyata suasana menjadi kaku, sehingga kemungkinan untuk menjalin kerja sama pun menjadi semakin kecil (Young \& Rogers 1998). Kecemasan sosial membuat remaja menjadi malas untuk berinteraksi di dunia nyata karena merasa lebih menyenangkan untuk berinteraksi dengan teman online.

Dari beberapa hasil penelitian diatas bahwa interaksi sosial online, kecemasan sosial dan kecanduan internet merupakan variabel yang perlu dilakukan dalam penelitian. Peneliti mengajukan suatu penelitian mengenai pengaruh interaksi sosial online dan kecemasan sosial dengan kecanduan internet pada remaja.

\section{METODOLOGI PENELITIAN}

Penelitian ini menggunakan pendekatan kuantitatif dengan jenis penelitian yang dipakai adalah ex-post facto. Tujuan penelitian ini mengungkap sebuah data yang telah dimiliki tanpa memberikan manipulasi pada variabel penelitian dan menunjukan hubungan sebab-akibat pada variabel bebas (interaksi sosial online dan kecemasan sosial) dan variabel terikat (kecanduan internet).

Penelitian ini dilaksanakan di kabupaten Purbalingga, tempat penelitian dilaksanakan di 3 SMA (Sekolah Menengah Atas) yang ada di Purbalingga. Peneliti 
memilih Purbalingga sebagai tempat penelitian karena dari data survei Asosiasi Penyelenggara Jasa Internet Indonesia pada tahun 2018 menunjukkan 55,7\% kontributor pengguna internet di Indonesia berasal dari Jawa, 14,3\% berasal dari Jawa Tengah. Hal itu menjadikan peneliti tertarik untuk meneliti salah satu kabupaten di Jawa Tengah, akhirnya peneliti memilih kabupaten Purbalingga sebagai tempat penelitian karena memiliki jumlah penduduk yang cukup besar, serta sudah banyak remaja yang menggunakan internet dan akses internet yang bagus serta belum pernah dilakukan penelitian mengenai kecanduan internet.

Selain itu, peneliti memilih remaja SMA karena remaja umur 15 sampai 19 tahun merupakan pengguna internet tertinggi sebesar 91\% dibandingkan kategori umur yang lain. Pada tiga SMA yang dijadikan tempat penelitian juga menyediakan sarana berupa internet atau Hot Spot di sekolah, dan daerah di sekitar sekolah yang menjadi tempat tinggal siswa memiliki akses internet bagus, serta ketiga sekolah tersebut mewakili daerah kota, daerah peralihan kota dengan desa dan daerah pedesaan. Kondisi demikian membuat peneliti memandang remaja ketiga SMA ini tepat untuk dijadikan sebagai objek penelitian.

Waktu pengambilan data penelitian ini diambil pada tanggal 6 Mei 2019 sampai 14 Mei 2019 antara pukul 07.00-15.00 WIB dengan menyerahkan surat izin penelitian terlebih dahulu dan dilakukan pendistribusian angket penelitian.

Populasi dalam penelitian ini yaitu remaja di kabupaten Purbalingga. Jumlah populasi dalam penelitian ini adalah 9.338 siswa dari 16 SMA negeri dan swasta di kabupaten Purbalingga tahun ajaran 2018/2019. Pengambilan sampel penelitian menggunakan teknik Multistage Random Sampling yaitu 366 siswa SMA. Berdasarkan pendapat Martens (2014) teknik multistage random sampling merupakan kombinasi strategi pengambilan sampel.

Teknik pengumpulan data dalam penelitian ini menggunakan 3 angket berbentuk skala yaitu angket tentang kecanduan internet, tentang interaksi sosial online, dan tentang kecemasan sosial dengan menggunakan skala likert yang terdiri dari 5 pilihan jawaban. Skala kecanduan internet dikembangkan oleh Tao et al. Skala interaksi sosial online menggunakan konsep Yuan Tian, Fanchang Kong, dan Zongkui Zhou. Skala kecemasan sosial yang akan digunakan dalam penelitian ini adalah mengadopsi La Greca dan Lopez

\section{HASIL DAN PEMBAHASAN}

Data yang dipaparkan dalam Gambar 1 menunjukkan 4,90\% mendapatkan skor kecanduan internet dengan kategori tinggi, $83,30 \%$ memiliki skor kecanduan internet 
dengan kategori sedang, dan 11,70\% mendapatkan skor kecanduan internet dengan kategori rendah.

Kategorisasi dalam pengelompokan skor individu menggunakan rata-rata ideal, hal ini dimaksudkan agar proposrsi hasil statistik kategorisasi tidak selalu mengikuti kurva normal. Kategorisasi pada skala kecanduan internet dapat dilihat pada Gambar 1.

\section{Gambar 1. Histogram Kategorisasi Kecanduan Internet}

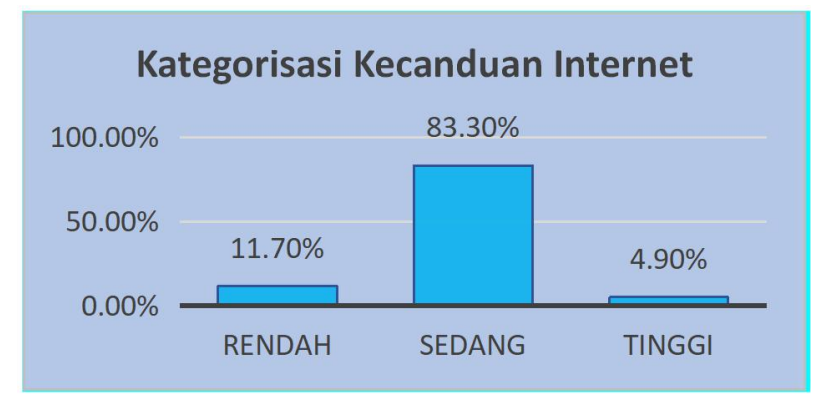

Kemudian untuk kategorisasi dalam pengelompokan skor individu menggunakan rata-rata ideal, hal ini dimaksudkan agar proposrsi hasil statistik kategorisasi tidak selalu mengikuti kurva normal. Kategorisasi pada skala interaksi sosial online dapat dilihat pada Gambar 2..

\section{Gambar 2. Histogram Kategorisasi Interaksi Sosial Online}

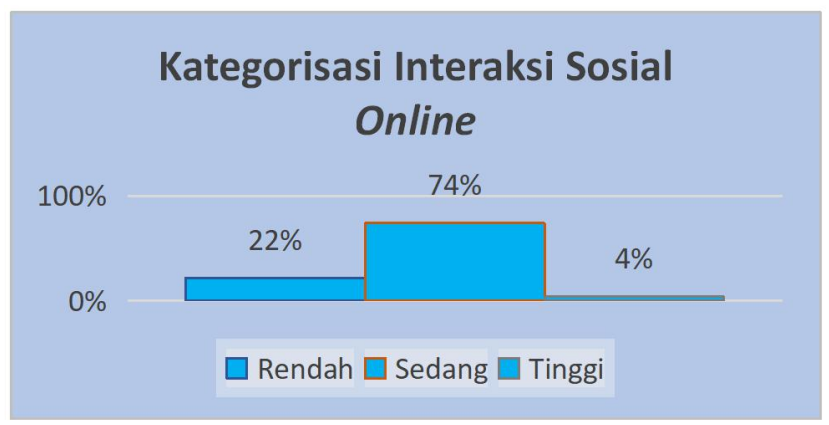

Data yang dipaparkan dalam Gambar 2 menunjukkan 4\% mendapatkan skor interaksi sosial online dengan kategori tinggi, $74 \%$ mendapatkan skor interaksi sosial online dengan kategori sedang, dan $22 \%$ mendapatkan skor interaksi sosial online dengan kategori rendah. 
Kemudian untuk kategorisasi dalam pengelompokan skor individu menggunakan rata-rata ideal, hal ini dimaksudkan agar proposrsi hasil statistik kategorisasi tidak selalu mengikuti kurva normal. Kategorisasi pada skala kecemasan sosial dapat dilihat pada Gambar 3

Gambar 3. Histogram Kategorisasi Kecemasan Sosial

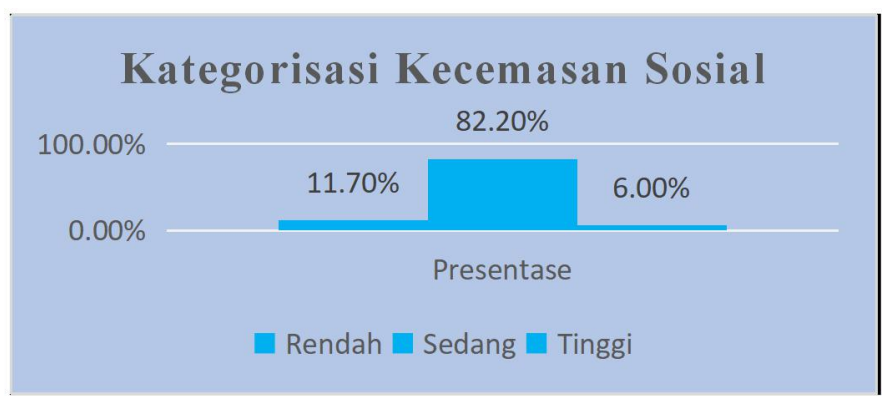

Data yang dipaparkan dalam Gambar 2 memiliki skor kecemasan sosial dengan menunjukkan $11,70 \%$ memiliki skor kategori rendah.

kecemasan sosial dengan kategori tinggi, Hasil uji regresi pengaruh interaksi $82,20 \%$ memiliki skor kecemasan sosial dengan kategori sedang, dan $11,70 \%$

sosial online dan kecemasan sosial terhadap kecanduan internet, ditunjukkan pada tabel 1.

\begin{tabular}{|c|c|c|c|c|c|c|c|c|c|}
\hline \multirow[t]{2}{*}{ Model } & \multirow[t]{2}{*}{$\mathrm{R}$} & \multicolumn{8}{|c|}{$\begin{array}{r}\text { Tabel 1. Hasil Analisis Regresi Ganda } \\
\text { Adjusted }\end{array}$} \\
\hline & & Square & R Square & $\begin{array}{l}\text { of the } \\
\text { Estimate }\end{array}$ & $\begin{array}{l}\text { R Square } \\
\text { Change }\end{array}$ & $\begin{array}{c}\mathrm{F} \\
\text { Change }\end{array}$ & $\mathrm{df1}$ & $\mathrm{df} 2$ & $\begin{array}{l}\text { Sig. F } \\
\text { Change }\end{array}$ \\
\hline 1 & $\begin{array}{c}.580 \\
\mathrm{a}\end{array}$ & .337 & .333 & 11.561 & .337 & 92.212 & 2 & 363 & .000 \\
\hline
\end{tabular}

Tabel 1 menunjukkan informasi tentang besarnya pengaruh variabel interaksi sosial online dan kecemasan sosial terhadap kecanduan internet. Pengaruh disimbolkan dengan dengan $\mathrm{R}$ (korelasi). Seperti yang terlihat pada tabel nilai pada kolom $\mathrm{R}$ sebesar 0,580 .
Hal ini menunjukkan bahwa pengaruh antara variabel interaksi sosial online dan kecemasan sosial terhadap kecanduan internet adalah $58,0 \%(0,580 \times 100 \%)$. Sumbangannya atau koefisien determinasinya sebesar $0,337 \%$ atau $33,7 \%$ dan $66,3 \%$ diasumsikan peneliti merupakan sumbangan 
pengaruh dari variabel lain yang belum diteliti dalam penelitian ini.

Penelitian ini membuktikan bahwa interaksi sosial online dan kecemasan sosial menjadi prediktor kecanduan internet pada remaja. Hal ini berarti hipotesis yang berbunyi interaksi sosial online dan kecemasan sosial mampu memprediksi kecanduan internet pada remaja terbukti. Hasil penelitian ini sejalan dengan penelitian yang membuktikan bahwa interaksi sosial online dan kecemasan sosial berhubungan dengan kecanduan internet (Huan, Ang, dan Chye, 2014; Lee-Won, Herzog, dan Park, 2015).

Kecanduan internet terdiri atas aspek keasyikan, withdrawal, toleransi, kesulitan dalam mengendalikan, tidak peduli pada konsekuensi berbahaya, komunikasi dan ketertarikan sosial hilang, serta menghindari dan mengurangi mood dysporic (Tao et al., 2010). Individu yang terlihat dari aspek keasyikan dalam menggunakan internet memiliki pemikiran tentang mengurangi kecemasan sosial dengan menghabiskan sebagian besar waktunya untuk mengakses internet, termasuk untuk menggunakan interaksi sosial online. Interaksi sosial online sering digunakan individu karena banyaknya aplikasi yang membuat individu merasa asyik.

Hal ini sesuai dengan pendapat Zhang, Li, (2015) yang menyatakan bahwa pemikiran tentang diri yang tidak bisa diterima dalam dunia nyata merupakan faktor utama yang menjadikan orang yang mengalami kecemasan sosial untuk mencari tempat lain yang bisa diterima yaitu internet.

Hal ini sejalan dengan pendapat Mazzoni, Baiocco, Cannata, dan Dimas, (2016) yang menyatakan bahwa remaja yang mengalami kecemasan sosial merasa nyaman menggunakan interaksi sosial online karena timbal balik dari internet, termasuk disini emosional suport online.

Sikap positif individu yang menyukai interaksi sosial online dan orientasi yang lebih kuat untuk mendapatkan lebih banyak teman online daripada mengalami kecemasan sosial ketika berhubungan dengan orang lain secara langsung dapat berkontribusi pada kecanduan internet $\mathrm{Hal}$ ini terjadi karena ketika individu sudah asik menggunakan internet karena berbagai fasilitas yang ditawarkan, maka individu tersebut merasa tidak peduli pada konsekuensi berbahaya ketika menggunakan interaksi sosial online untuk mengurangi kecemasan sosial.

Hal ini terjadi karena individu merasa nyaman berkomunikasi dengan orang lain melalui interaksi sosial online dibandingkan interaksi sosial tatap muka secara langsung. Selain itu ketika mencari informasi dari orang lain melalui interaksi sosial online lebih cepat dan bisa darimana saja. 
Individu yang berusaha keras memanfaatkan interaksi sosial online untuk mengurangi kecemasan, tetapi menimbulkan efek negatif berupa kecanduan internet. Kecanduan internet pada remaja berakibat pada tidak mampu mengikuti pelajaran sekolah dengan maksimal, suka berbohong, kurang berinteraksi dengan teman sebaya, mencuri, menjadi korban kejahatan dunia maya, terlambat melakukan berbagai hal, kurang tidur, dan kebiasaan makan yang tidak teratur (Montag dan Reuter, 2017 ).

Hasil analisis data penelitian ini menunjukkan bahwa variabel interaksi sosial online dan kecemasan sosial mampu memprediksi variabel kecanduan internet sebesar 33,7\%. Selebihnya dipengaruhi faktor lain sebesar $66,3 \%$ yang tidak diteliti dalam penelitian ini. Hal ini berarti bahwa terdapat pengaruh interaksi sosial online dan kecemasan sosial terhadap kecanduan internet pada remaja. Dengan demikian, dapat dikatakan bahwa salah satu hal yang dapat menjadikan remaja mengalami kecanduan internet adalah interaksi sosial online dan kecemasan sosial.

Dari hasil penjelasan berbagai penelitian di atas, maka dapat disimpulkan bahwa adanya interaksi sosial online dan kecemasan sosial memiliki hubungan positif terhadap kecanduan internet pada remaja, sehingga dapat dikatakan bahwa kedua variabel interaksi sosial online dan kecemasan sosial merupakan prediktor yang dapat memengaruhi kecanduan internet pada remaja.

\section{SIMPULAN}

Kesimpulan yang dapat diambil dari analisis data penelitian yang telah dilaksanakan adalah terdapat pengaruh signifikan yang positif berdasarkan hasil persamaan regresi antara variabel interaksi sosial online dan variabel kecemasan sosial secara bersamasama terhadap kecanduan internet pada remaja dengan besarnya pengaruh $33,7 \%$ dan sisanya dipengaruhi oleh variabel lain.

\section{DAFTAR RUJUKAN}

(APJII), A. P. J. I. I. (2019). Hasil Survei Penetrasi dan Perilaku Pengguna Internet Indonesia 2018. Retrieved from https://apjii.or.id/survei

Crutzen, R., de Nooijer, J., Brouwer, W., Oenema, A., Brug, J., \& de Vries, N. K. (2011). Strategies to facilitate exposure to internet-delivered health behavior change interventions aimed at adolescents or young adults: a systematic review. Health Education \& Behavior, 38(1), 49-62.

Fonseca, C. (2015). A Parent's Guide to Social Anxiety Raising the Shy Child Advice for Helping Kids Make Friends, Speak Up, and Stop Worrying. Waco, Texas, USA: Prufrock Press Inc.

Huang, H. (2014). Social Media Generation in Urban China. New York Dordrecht London: Springer Publishing Company.

Kuss, D. J., Van Rooij, A. J., Shorter, G. W., 
Griffiths, M. D., \& van de Mheen, D. (2013). Internet addiction in adolescents: Prevalence and risk factors. Computers in Human Behavior, 29(5), 1987-1996.

Lee, Y.-H., Ko, C.-H., \& Chou, C. (2015). Re-visiting Internet addiction among Taiwanese students: A cross-sectional comparison of students' expectations, online gaming, and online social interaction. Journal of Abnormal Child Psychology, 43(3), 589-599.

Lee, Y.-H., \& Wu, J.-Y. (2013). The indirect effects of online social entertainment and information seeking activities on reading literacy. Computers \& Education, 67, 168-177.

Lee, Z. W.-Y., \& Cheung, C. M.-K. (2014). Problematic use of social networking sites: The role of self-esteem. International Journal of Business and Information, 9(2).

Merikangas, K. R., He, J., Burstein, M., Swanson, S. A., Avenevoli, S., Cui, L., ... Swendsen, J. (2010). Lifetime prevalence of mental disorders in US adolescents: results from the National Comorbidity Survey ReplicationAdolescent Supplement (NCS-A). Journal of the American Academy of Child \& Adolescent Psychiatry, 49(10), 980-989.

Morahan-Martin, J., \& Schumacher, P. (2003). Loneliness and social uses of the Internet. Computers in Human Behavior, 19(6), 659-671.

Musetti, A., Cattivelli, R., Giacobbi, M., Zuglian, P., Ceccarini, M., Capelli, F., ... Castelnuovo, G. (2016). Challenges in internet addiction disorder: is a diagnosis feasible or not? Frontiers in Psychology, 7, 842.
Nakaya, A. C. (2015). Internet and Social Media Addiction. San Diego, United States of America: Reference Point Press.

Norris, M. L. (2007). HEADSS up: Adolescents and the Internet. Paediatrics \& Child Health, 12(3), 211216.

Perdew, L. (2014). Internet addiction. North Mankato, Minnesota, United States of America: Abdo Publishing.

Shaw, M., \& Black, D. W. (2008). Internet addiction. CNS Drugs, 22(5), 353-365.

Smahel, D., Brown, B. B., \& Blinka, L. (2012). Associations between online friendship and Internet addiction among adolescents and emerging adults. Developmental Psychology, 48(2), 381.

Tao, R., Huang, X., Wang, J., Zhang, H., Zhang, Y., \& Li, M. (2010). Proposed diagnostic criteria for internet addiction. Addiction, 105(3), 556-564.

Wulandari, R. (2015). hubungan antara kontrol diri dengan kecanduan game online pada remaja di warnet lorong Cempaka dalam kelurahan 26 Ilir Palembang. Jurnal Fakultas Psikologi Universitas Bina Darma Palembang.

Young, Kimberly S, \& Rogers, R. C. (1998). The relationship between depression and Internet addiction. Cyberpsychology \& Behavior, 1(1), 25-28.

Zhang, H., Li, D., \& Li, X. (2015). Temperament and problematic Internet use in adolescents: A moderated mediation model of maladaptive cognition and parenting styles. Journal of Child and Family Studies, 24(7), 1886-1897. 
